\title{
Opportunities and challenges in producing a regional online neonatal medicines formulary
}

\author{
Laura Dalton, Chris Day
}

The Yorkshire and Humber Neonatal Operational Delivery Network, UK

\section{Background and aims}

Developing regional guidelines aims to make clinical service more equitable across organisations. Research in neonatal units in the Yorkshire and Humber region showed that there was variation in doses prescribed, preparation, final concentrations and the administration of the most commonly used medicines.

Producing a centralised online medicines formulary accessible to units in the Yorkshire and Humber Neonatal Operational Delivery Network (ODN) aims to align practice across the region.

\section{Methods}

\begin{tabular}{|l|l|l|l|l|l|}
\hline $\begin{array}{l}\text { Monographs } \\
\text { written by } \\
\text { project lead }\end{array}$ & $\begin{array}{l}\text { Circulated to } \\
\text { steering group } \\
\text { for review }\end{array}$ & $\begin{array}{l}\text { Alterations made } \\
\text { based on } \\
\text { recommendations }\end{array}$ & $\begin{array}{l}\text { Monographs } \\
\text { published on } \\
\text { ODN website }\end{array}$ & $\begin{array}{l}\text { Neonatal units link to } \\
\text { monographs from their }\end{array}$ \\
\hline
\end{tabular}

- Monographs have a standard layout containing information about indications, dosing, preparation, administration, known compatibilities and incompatibilities, additional information and references.

- 27 drug monographs have been published to date and the formulary continues to expand.

- Neonatal units access these monographs through their local online formularies or guidelines.

\section{Opportunities}

- Collaborative working across the network

- Challenging historical practice with up to date evidence

- Improve accuracy and confidence in prescribing medicines on neonatal units

- Provide clear guidance on preparation and administration of medicines

- Provide accessible medicines compatibility information

- Reduce error by reducing the need to make new infusions for transfer or when arriving in receiving unit

- Reduce waste by transferring babies on appropriately made infusions that can be continued in the receiving unit

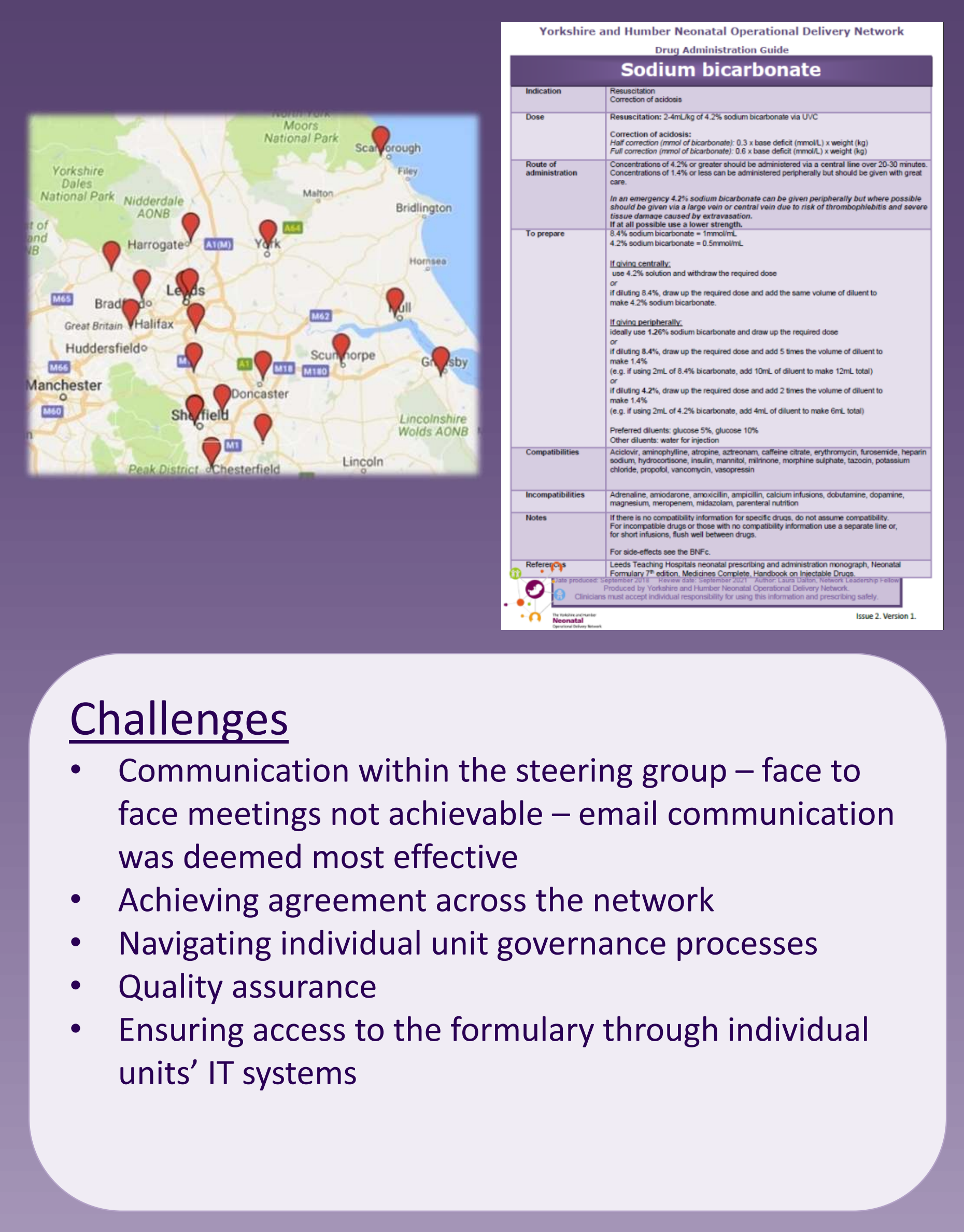

\section{Conclusions}

Achieving pharmacological consensus across a neonatal ODN can be challenging. Focusing on the aim to improve patient care is essential in overcoming challenges and making the project a success.

Feedback from nursing, medical and pharmacy staff across the region has been positive in terms of confidence in correct prescribing and clarity of preparation and administration instructions, particularly in emergency and time-sensitive clinical situations. 